\title{
O HORROR MELANCÓLICO: RESENHA DE BILE NEGRA, DE OSCAR NESTAREZ
}

Louise Farias da Silveira

Recebido em 03 mar 2020. Louise Farias da Silveira possui graduação em Letras Aprovado em 27 mar 2020. Português/Inglês (2012) pela Universidade Federal do Rio Grande (FURG) e mestrado em Letras na área de concentração História da Literatura (2015) pela mesma instituição. Lecionou na rede de ensino fundamental do município de São José do Norte, atuou como professora-bolsista do Núcleo de Língua Inglesa do Programa Idiomas sem Fronteiras (ISF) na Universidade Federal do Rio Grande e como professora substituta da área de Língua Inglesa na referida universidade. Seus interesses de pesquisa relacionam-se aos seguintes temas: Literatura Brasileira, Literatura Comparada e Insólito Ficcional. É professora do Instituto Federal Catarinense (IFC), atuando no Campus Santa Rosa do Sul, e doutoranda em Estudos Literários pela Universidade Federal de Santa Maria (UFSM). 
Ooh, I'll top the bill, I'll overkill I have to find the will to carry on (Queen, The Show Must Go On)

Bile Negra, publicado em 2017 pela Empíreo Editora (hoje Pyro), é o primeiro romance do escritor paulistano Oscar Nestarez, que até então publicara Sexorcista e outros relatos insólitos (2014) e Horror adentro (2016). A edição apresenta uma capa nas cores preto e branco, com o
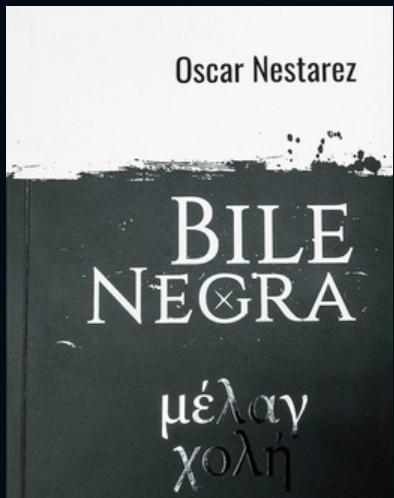
predomínio do tom escuro. A primeira e a segunda orelha do livro apresentam, respectivamente, a biografia do autor e uma breve introdução do tema, explicando sua relação com os termos gregos

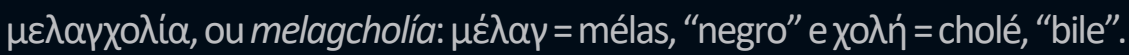

Já na quarta capa, um questionamento provoca o leitor: "O que acontece quando perdemos as rédeas de nossa própria mente?" Abaixo, um resumo contextualiza a narrativa, mencionando a personagem Vex e resumindo os princípios da Teoria Humoral, em torno da qual o enredo será desenvolvido.

O capítulo um inicia, o leitor é situado em uma sala de espera de um consultório psiquiátrico. O narrador em primeira pessoa analisa o espaço ao seu redor e questiona-se a respeito dos companheiros que ali aguardam para serem atendidos, atenta para o fato de eles estarem com os pulsos cobertos, diferente de si, que não vê razão em esconder as próprias cicatrizes.

Antes de apresentar o narrador Vex, os trinta e dois capítulos do romance precedidos por uma epígrafe, retirada da canção "Flores 
Astrais", da banda brasileira Secos e Molhados: "O verme passeia na lua cheia". O intrigante trecho fará sentido posteriormente, ao longo da leitura da obra. Ademais, impresso em páginas pretas, em fonte itálica, as escolhas gráficas para o prólogo indicam tratar-se essa de uma história a parte daquela principal, ainda que relacionada com a mesma - essa formatação e temática se repetirá em outros capítulos.

Retornando ao capítulo inicial, Vex é atendido pela doutora Norma, a quem relata sua recente melhora, creditada por ele às descobertas que teriam feito juntos nas seções anteriores. A ambientação das primeiras cenas e os diálogos apontam para um provável romance psicológico, focado nas aflições de um narrador e seus distúrbios emocionais.

Ao relatar o impacto psicológico sofrido após um acontecimento traumático, seguido de um período inconsciente, Vex descreve aqueles que foram os piores meses da sua vida, quando fora tomado por "uma angústia tão grande que eu não conseguia pensar em nada que não fosse medonho [...] Era como perder as rédeas da mente. A cabeça disparava por lugares tenebrosos" (NESTAREZ, 2017, p.22).

As descrições das experiências vivenciadas pelo narradorprotagonista durante seu período depressivo nos remetem a textos consagrados, no qual a temática foi tratada com profundidade e sensibilidade. Não há como não lembrar da personagem Esther em A Redoma de Vidro, da escritora norte-americana Sylvia Plath, para quem o padecimento sob uma existência obsessivamente melancólica a fazia sentir impotente: "Para a pessoa dentro da 
redoma de vidro, vazia e imóvel como um bebê morto, o mundo em si é um sonho ruim" (PLATH, 2005, p.237 - tradução nossa) ${ }^{1}$.

Todavia, a redoma sob a qual Vex se encontra é abordada por Nestarez sob outro ponto de vista: o do horror. O leitor atento há de perceber o selo colado à capa do livro que tem em mãos: Prêmio ABERST $^{2} 2018$ de Melhor Romance de Horror. A afiliação do autor à literatura do medo não é um acaso, uma vez que o ficcionista dedicase aos estudos da literatura de horror, tendo publicado Poe e Lovecraft: um ensaio sobre o medo na literatura (2013). Doutorando em Estudos Comparados de Literaturas de Língua Portuguesa pela USP, o escritor também colabora mensalmente com a Revista Galileu.

Outro fator que transcende os limites da ficção e leva as vivências do autor para dentro de sua obra é o espaço ficcional que serve de cenário para a primeira metade da narrativa, ambientada na cidade de São Paulo. O movimento intenso da capital e as alterações climáticas parecem refletir diretamente no estado de espírito da personagem:

Nuvens carregadas se acumularam, e a aragem seca deu lugar a um vento úmido. Gostava muito de quando São Paulo me surpreendia assim, sem mais nem menos. E a leve irritação causada pelo calor, que procurei esconder da doutora por considerar irrelevante, deu lugar a um inabalável ímpeto realizador. Sentia-me, naquele final de tarde, maior do que no começo do dia. (NESTAREZ, 2017, p.18)

Assim como o clima inconstante da metrópole, Vex também percorre um caminho contrário à linearidade. Ora sente-se

1 "To the person in the bell jar, blank ans stopped as a dead baby, the world itself is the bad dream."

2 Associação Brasileira de Escritores de Romance Policial, Suspense e Terror. 
empolgado e dilui-se em meio aos tantos sujeitos da mais populosa cidade brasileira, saindo de Higienópolis, passando por Pinheiros; ora refugia-se com os amigos Sandra, Téo, Vera, Môa e Caio Graco (CG) em um bar na Mooca, "à margem do movimento frenético que é a passagem do tempo em São Paulo" (NESTAREZ, 2017, p.19).

Referências à cultura pop são constantes na obra; nessas primeiras páginas bandas de pós-punk como Cocteau Twins, Dead Can Dance e Sisters of Mercy embalam a narração e mostram sua afiliação com uma atmosfera da subcultura gótica da década de 1980. Nestarez vai dos clássicos do jazz ao rock alternativo, mostrando sua versatilidade em uma prosa que se delineia entre a norma culta da língua e o palavreado vulgar e obsceno utilizado em um informal diálogo entre amigos.

A trama desenrola-se mostrando o relacionamento amoroso, embora confuso, entre Vex e Sandra, os quais compartilham de "fugas mentais" similares. Não por acaso a personagem feminina vai ser a primeira a ser acometida pelo mal que se espalhará no plano ficcional como uma epidemia, lançando o protagonista uma vez mais a uma jornada caótica em busca de sobrevivência.

Seria falso dizer que o insólito irrompe na narrativa de maneira abrupta. Nestarez conduz seu leitor através da perspectiva de um narrador em primeira pessoa que aparenta perceber uma mudança gradual no universo ao seu redor, seja observando as escleras escurecidas de algumas pessoas que vivenciam uma suposta tristeza, seja ao comentar profeticamente "que algo tremendo estava prestes a acontecer" (NESTAREZ, 2017, p.28).

A Bile Negra do título é evocada no plano ficcional através do livro Bible of the Black Bile, um tratado de medicina pré-moderna 
publicado sob o pseudônimo Grigora. O texto, mistura de ciência, filosofia e ocultismo, chega às mãos de Vex para que esse o traduza ao Português. Môa explica ao amigo o que seria a bile negra: "É uma antiga teoria médica segundo a qual a nossa saúde se mantinha pelo equilíbrio entre quatro humores: sangue, fleuma, bile amarela e bile negra" (NESTAREZ, 2017, p.32). Os humores associam-se, respectivamente, a diferentes estados de espírito: à alegria e ao amor; à irritação e à raiva; à moderação e à frieza; e, por último, ao desânimo e à tristeza.

A partir daí o protagonista interessa-se pelo tema, tomando ciência da suposta associação dos humores com fluídos corporais específicos proposta por Hipócrates. Ainda, de acordo com a Teoria Humoral, o desequilíbrio de um dos humores, tanto em relação ao excesso ou à falta de um deles, acarretaria o adoecimento do ser humano, visão essa aceita pela ciência médica até meados do século XVII.

Deste modo, a produção excessiva de bile negra provocaria a subjugação do indivíduo, que se entregaria à melancolia ou, como conhecido na contemporaneidade, ao transtorno depressivo maior. Vex reconhece o absurdo da teoria obscurantista e ultrapassada, mas não deixa de perceber semelhanças entre um suposto magnetismo da bile negra e os acontecimentos estranhos ao seu redor, especialmente após presenciar um ataque convulsivo noturno de Sandra e experenciar pensamentos "tenebrosos, nada menos do que tenebrosos" (NESTAREZ, 2017, p.46) ao entrar em contato com suas córneas escurecidas.

Ao longo da trama, o narrador faz uso de diferentes vocábulos para expressar as cenas assustadoras que presencia e 
os pensamentos desconfortáveis que elas Ihe evocam. O escritor estadunidense H. P. Lovecraft, em seu longo ensaio $O$ Horror Sobrenatural na Literatura, discorre a cerca da estética da literatura de horror sobrenatural, apresentando um tratado do gênero. Nas palavras do autor:

O único teste para o verdadeiro horror é simplesmente este: se suscita ou não no leitor um sentimento de profunda apreensão, e de contato com esferas diferentes e forças desconhecidas; uma atitude sutil de escuta ofegante, como à espera do ruflar de asas negras ou do roçar de entidades e formas nebulosas nos confins extremos do universo conhecido. (LOVECRAFT, 1987, p.6-7)

Para Lovecraft, a ficção de horror deve apresentar uma atmosfera de terror sufocante, suspendendo as leis da natureza que até então pareciam inflexíveis para o leitor. Em Bile Negra, essa transgressão insólita irrompe no cotidiano de Vex quando, ao observar Sandra inconsciente na UTI, ele presencia uma cena que não consegue explicar racionalmente:

As sanguessugas começaram a sair das órbitas, a vazar muito lentamente em direção ao teto, recortando o ar, retorcendo-se - na verdade, eram como serpentes. Como serpentes hipnotizandome, sinuosas e em absoluto silêncio [...] Falho e sempre falharei em descrever aquilo. (NESTAREZ, 2017, p.57)

Vex falha em descrever o que presenciara, pois desconhece tais "abominações", como posteriormente as define. Todavia, sabe estar diante de algo horripilante, entregando-se ao medo que é, para Lovecraft, a emoção mais antiga vivenciada pelo homem. Sua 
mente, que antes pensara estar sob controle, é dominada pelos pensamentos mais assustadores e traumáticos.

A bile negra, até então apenas uma teoria obscura, parece derramar-se no horror da melancolia, espalhando-se pela narrativa em uma fuga incansável do narrador-protagonista para manter-se são. Assim, a partir da segunda metade da obra, a trama ganha um ritmo intenso que se desenvolve ao longo de uma viagem em busca de refúgio de São Paulo até a pequena cidade de Não-Me-Toque, no interior do Rio Grande do Sul.

Nestarez não erra ao fazer de sua história de horror também uma road novel, na qual a estrada não apenas proporciona uma experiência que mudará a vida do protagonista, como também é cenário para monstruosidades lovecraftianas humanamente personificadas em indivíduos aniquilados por pensamentos depressivos.

A música da banda britânica Queen que toca no rádio em uma das cenas faz referência a esse deslocamento constante de Vex e das outras personagens que aparecem pelo caminho, convidando o leitor a acompanhar o desenvolvimento desse romance de horror psicológico à brasileira. Afinal, The show must go on!

\section{REFERÊNCIAS}

LOVECRAFT, Howard Phillips (1987). O horror sobrenatural na literatura. Rio de Janeiro: Francisco Alves.

NESTAREZ, Oscar (2014). Sexorcista e outros relatos insólitos. São Paulo, Livrus.

NESTAREZ, Oscar (2016). Horror adentro. São Paulo, Kazuá.

NESTAREZ, Oscar (2017). Bile negra. São Paulo: Empíreo.

PLATH, Sylvia (2005). The bell jar. New York: Harper Perennial. 